\title{
Genetic subgroup of small ruminant lentiviruses that infects sheep homozygous for TMEM154 frameshift deletion mutation $A 4^{\Delta} 53$
}

Michael L Clawson ${ }^{*}$, Reid Redden², Gennie Schuller ${ }^{1}$, Michael P Heaton ${ }^{1}$, Aspen Workman ${ }^{1}$, Carol G Chitko-McKown', Timothy PL Smith ${ }^{1}$ and Kreg A Leymaster ${ }^{1}$

\begin{abstract}
Small ruminant lentivirus (SRLV) infections of sheep are influenced by genetics on both the host and pathogen sides. Genetic variation in the ovine transmembrane 154 (TMEM154) gene associates with infection susceptibility, and distinct SRLV genetic subgroups infect sheep in association with their TMEM154 diplotypes. In this study, a novel SRLV subgroup was identified that naturally infected sheep with various TMEM154 diplotypes, including those homozygous for a rare frameshift mutation (A4 delta53), which is predicted to abolish TMEM154 protein function. Thus, these SRLVs may infect sheep that lack functional TMEM154, and may not be restricted by TMEM154 diplotypes in establishing infections.
\end{abstract}

\section{Introduction, methods and results}

Small ruminant lentiviruses (SRLVs) are genetically diverse retroviruses that infect monocytes, macrophages, dendritic cells, and microglial cells of domestic sheep, goats, and wild ruminants [1-4]. Infections persist for the lifetime of the host, causing chronic inflammation and a slow progression to disease $[5,6]$. Common symptoms of SRLV infection in sheep include interstitial pneumonia with dyspnea, indurative mastitis, and cachexia [7]. There are no available preventative vaccines or cures for SRLVs, and the disease affects sheep and goats in the U.S. and around much of the world [8-11].

In sheep, there is a strong genetic component to the relative risk of SRLV infection on both the host and pathogen sides $[12,13]$. On the host side, genetic variation in the ovine transmembrane 154 (TMEM154) gene associates with SRLV infection susceptibility [12,14]. The biological function of TMEM154 is unknown; however, it is predicted to be a type I membrane protein based on its amino acid sequence. Twelve non-synonymous SNPs have been detected in regions of TMEM154 that encode predicted

\footnotetext{
* Correspondence: mike.clawson@ars.usda.gov

'United States Department of Agriculture (USDA) Agricultural Research Service (ARS), U.S. Meat Animal Research Center (USMARC), State Spur 18D, Clay Center, NE 68933, USA

Full list of author information is available at the end of the article
}

leader or extracellular domains of the protein, giving rise to 12 haplotypes that each encode different isoforms (Table 1) [12]. Haplotypes 1, 2, and 3 are the most common haplotypes found in sheep, and all three have an effect on SRLV susceptibility. Sheep with a copy of either haplotype 2 or 3 , both of which encode a glutamate amino acid residue at position 35 (E35) of the extracellular portion of TMEM154, have an increased risk of SRLV infection. Conversely, sheep homozygous for haplotype 1, which encodes a lysine residue at position 35 (K35), have a decreased risk of infection (Table 1) [12,15].

On the pathogen side, two SRLV subgroups defined by genetic variation within segments of proviral gag and env genes, associate with alleles of the ovine TMEM154 E35K polymorphism [13]. SRLV subgroup 1 associates with homozygous and hemizygous TMEM154 K35 genotypes with the $\mathrm{K}$ allele encoded by haplotype 1 , and subgroup 2 associates with hemi-and homozygous TMEM154 E35 genotypes with the $\mathrm{E}$ allele encoded by haplotypes 2 or 3 (Table 1) [13]. Thus, some SRLVs have adapted to infect sheep with distinct TMEM154 E35K genotypes and can influence TMEM154 E35K susceptibility to infection.

The biology responsible for TMEM154 E35K associations with SRLV infection susceptibility, and SRLV subgroup associations with TMEM154 E35K genotypes is unknown. While a portion of TMEM154 is predicted to 
Table 1 Ovine TMEM154 haplotypes and their associations with infection susceptibility and SRLV subgroups

\begin{tabular}{|c|c|c|c|c|c|c|c|c|c|c|c|c|c|c|}
\hline \multirow[t]{2}{*}{ Haplotype } & \multicolumn{12}{|c|}{ Amino acid at position indicated } & \multirow[t]{2}{*}{ Allelic effect ${ }^{b}$} & \multirow[t]{2}{*}{ SRLV association } \\
\hline & $\overline{4^{a}}$ & 13 & 14 & 25 & 31 & 33 & 35 & 44 & 70 & 74 & 82 & 102 & & \\
\hline 1 & $\mathrm{R}$ & A & $\mathrm{L}$ & $\mathrm{T}$ & E & $\mathrm{D}$ & K & $T$ & $\mathrm{~N}$ & I & E & I & Less-susceptible & Subgroup 1 \\
\hline 2 & $\mathrm{R}$ & A & L & $\mathrm{T}$ & $\mathrm{E}$ & $\mathrm{D}$ & $\mathrm{E}$ & $\mathrm{T}$ & । & । & $\mathrm{E}$ & । & Highly-susceptible & Subgroup 2 \\
\hline 3 & R & A & L & $\mathrm{T}$ & $\mathrm{E}$ & D & $\mathrm{E}$ & $\mathrm{T}$ & $\mathrm{N}$ & I & E & । & Highly-susceptible & Subgroup 2 \\
\hline 4 & A & $P^{c}$ & $F^{c}$ & $P^{c}$ & $R^{c}$ & $T^{c}$ & $N^{c}$ & $W^{c}$ & $N A^{d}$ & NA & NA & NA & Unknown & $\begin{array}{l}\text { Unknown, can be infected } \\
\text { by Subgroup } 4 \text { (this study) }\end{array}$ \\
\hline 6 & R & $A$ & L & $\mathrm{T}$ & E & $D$ & E & $\mathrm{T}$ & $\mathrm{N}$ & I & Y & NA & Unknown & Unknown \\
\hline 9 & $\mathrm{R}$ & A & L & $\mathrm{T}$ & E & $\mathrm{N}$ & E & $\mathrm{T}$ & $\mathrm{N}$ & I & $E$ & I & Unknown & Unknown \\
\hline 10 & $\mathrm{R}$ & A & $\mathrm{H}$ & $\mathrm{T}$ & E & D & K & $\mathrm{T}$ & $\mathrm{N}$ & I & E & I & Unknown & Unknown \\
\hline 11 & R & A & L & I & E & D & $\mathrm{E}$ & $\mathrm{T}$ & $\mathrm{N}$ & I & $\mathrm{E}$ & I & Unknown & Unknown \\
\hline $12^{e}$ & R & A & L & $\mathrm{T}$ & E & $D$ & E & $\mathrm{T}$ & $\mathrm{N}$ & $\mathrm{F}$ & $E$ & I & Unknown & Unknown \\
\hline 13 & $\mathrm{R}$ & V & L & $\mathrm{T}$ & E & $\mathrm{N}$ & E & $\mathrm{T}$ & $\mathrm{N}$ & I & E & I & Unknown & Unknown \\
\hline 14 & R & A & L & $\mathrm{T}$ & E & D & E & $\mathrm{T}$ & $\mathrm{N}$ & I & E & $\mathrm{T}$ & Unknown & Unknown \\
\hline $15^{e}$ & R & A & L & $\mathrm{T}$ & Q & D & E & $\mathrm{T}$ & $\mathrm{N}$ & $\mathrm{F}$ & $E$ & I & Unknown & Unknown \\
\hline
\end{tabular}

${ }^{a}$ Numbers refer to amino acid positions in [GenBank:HM355886].

${ }^{\mathrm{b}}$ Does not account for SRLV subgroups.

'Result of frameshift mutation at amino acid position 4.

${ }^{\mathrm{d}}$ Not applicable due to preceding premature stop codon.

${ }^{\mathrm{E}}$ Haplotype observed in wild sheep.

extend from the host cell into the external milieu, it is not known if TMEM154 serves as a receptor, or coreceptor for SRLV attachment to the host cell, affects viral processing within the cell, or exit from it, or has a different biological function regarding SRLV infection. It is also not known if genetic variation in proviral gag and/or env directly causes SRLV subgroups to associate with TMEM154 E35K genotypes, or is in linkage disequilibrium with causal alleles elsewhere in the SRLV genome. However, given that SRLV subgroups and TMEM154 E35K genotypes associate with each other through apparent coevolution, TMEM154 is implicated as having a critical role in SRLV infections, leading us to hypothesize that sheep lacking functional TMEM154 may be completely resistant to SRLV infection.

TMEM154 A4A53 is a frameshift mutation that is predicted to abolish protein function [12]. With leader peptide, the ovine TMEM154 precursor protein encoded by haplotypes 1, 2, and 3 is 191 amino acids, and yields a mature protein of 161 amino acids once the predicted leader peptide has been removed [12]. TMEM154 A4A53 is part of haplotype 4 , and encodes a single nucleotide deletion at amino acid position four of the precursor protein which results in an extensive change of amino acid coding at and downstream of amino acid four, and the first of multiple premature stop codons starting at amino acid position 54 (Table 1). Consequently, a truncated 53 amino acid protein with little homology to other TMEM154 isoforms results from the mutation, and sheep that are homozygous for TMEM154 A4A53 constitute natural TMEM154 "knockouts". Although generally rare, the
TMEM154 A4D53 allele has been found in multiple sheep breeds in the U.S., and in sheep from Turkey, Iran, Spain, France, and India [12,16]. Thus, sheep homozygous for TMEM154 A4A53 are distributed throughout multiple geographical regions that may have their own distinct SRLV populations.

As part of a research surveillance program, a flock of approximately 250 sheep at North Dakota State University was sampled for SRLV infection and TMEM154 diplotypes. The flock was comprised of multiple breeds including Columbia, Dorset, Hampshire, and Katahdin. Members of the flock were approved for research use by the animal care and use committee of the North Central RegionSustainable Agriculture Research and Education program (Project Number FNC13-929). TMEM154 diplotypes were scored using a commercially run matrix-assisted laser desorption/ionization-time-of-flight mass spectrometry (MALDI-TOF MS) assay (GeneSeek, Lincoln, NE, USA) [16], and SRLV infection status was determined serologically using a commercially run competitive enzyme linked immunosorbent assay (cELISA), (GeneSeek [17]). Over 50\% of the flock was infected, including a Hampshire ewe and a Katahdin ewe that were both TMEM154 "4,4" diplotypes, and thus homozygous for TMEM154 A4A53 (Table 2).

The MALDI-TOF MS genotyping results for both of the TMEM154 "4,4" ewes, were confirmed with Sanger sequencing of TMEM154 DNA and CDNA amplified from their blood. The sequencing was conducted on PCR-generated amplicons of TMEM154 exons 1 and 2, and TMEM154 cDNA that was RT-PCR amplified with 
Table 2 SRLV-infected sheep sampled for proviral gag sequence

\begin{tabular}{lllll}
\hline Animal ID & Breed & Age & $\begin{array}{l}\text { TMEM154 } \\
\text { diplotype }\end{array}$ & $\begin{array}{l}\text { SRLV gag } \\
\text { GenBank \# }\end{array}$ \\
\hline 6004 & Dorset & 7 & 1,1 & KP120553 \\
7006 & Dorset & 6 & 1,1 & KP120547 \\
7056 & Columbia & 6 & 1,1 & KP120545 \\
8344 & Columbia & 5 & 1,1 & KP120540 \\
9032 & Columbia & 4 & 1,1 & KP120543 \\
261 & Dorset & 3 & 1,2 & KP120554 \\
6012 & Dorset & 7 & 1,2 & KP120549 \\
7028 & Dorset & 6 & 1,2 & KP120539 \\
9451 & Dorset & 4 & 1,2 & KP120541 \\
256 & Hampshire & 3 & 1,4 & KP120542 \\
6542 & Hampshire & 7 & 1,4 & KP120544 \\
7434 & Hampshire & 6 & 1,4 & KP120546 \\
8539 & Katahdin & 5 & 1,4 & KP120555 \\
9322 & Hampshire & 4 & 1,4 & KP120548 \\
15 & Hampshire & 3 & 2,4 & KP120552 \\
1150 & Hampshire & 2 & 4,4 & KP120550 \\
8540 & Katahdin & 5 & 4,4 & KP120551 \\
\hline & & & &
\end{tabular}

previously described reagents and conditions [12,16]. The sequences were produced with an ABI 3730 capillary sequencer (PE Applied Biosystems, Foster City, CA, USA) and assembled into complete contigs with Phred and Phrap [18,19], Polyphred (version 6.10), and Consed software [20], and visually genotyped. By DNA and cDNA sequence, both ewes were homozygous for TMEM154 A4 453 and had TMEM154 "4,4" diplotypes [GenBank: KP142216 - KP142219]. Thus, the TMEM154 DNA and corresponding mRNA sequences were identical, with no evidence of alternate splicing of TMEM154 at the transcript sequence level.

To verify the infection status of the two seropositive ewes with TMEM154 "4,4" diplotypes, and to characterize the SRLVs they were infected by, nested PCR for SRLV proviral gag was conducted on blood DNAs isolated from the two animals (Table 2). Additionally, the PCR was conducted on blood DNAs from 15 seropositive ewes of the same flock with other TMEM154 diplotypes, to determine if similar SRLVs had infected sheep with or without TMEM154 "4,4" diplotypes (Table 2). Previously described reagents, conditions, and methods were used for the PCR [13]. The amplicons were Sanger sequenced and assembled with Phred, Phrap, Polyphred (version 6.10), and Consed software [18-20]. All 17 seropositive ewes were confirmed positive for SRLV infection by proviral gag amplification and sequence.

In addition to the recent classification of SRLV subgroups 1 and 2 that associate with sheep TMEM154 E35K genotypes, SRLVs from around the world have been typed into major genotype groups A-E, and into subtypes within the genotype groups based on gag and/or pol variation [13,21-23]. To characterize the SRLVs infecting the North Dakota sheep, their gag sequences were compared to 1) those of SRLVs from North America and elsewhere in the world, and 2) the top ten closest blast matches to the gag sequence from one of the infected TMEM154 "4,4" ewes in a Neighbor-Net phylogenetic network (Figure 1) and a Neighbor-Joining tree (Figure 2), (see Additional file 1 for sequence information). The network was constructed as SRLVs can have recombinant genomes [24,25], including those that comprise subgroups 1 and 2 [13], and the network accounted for recombinant sequences. The

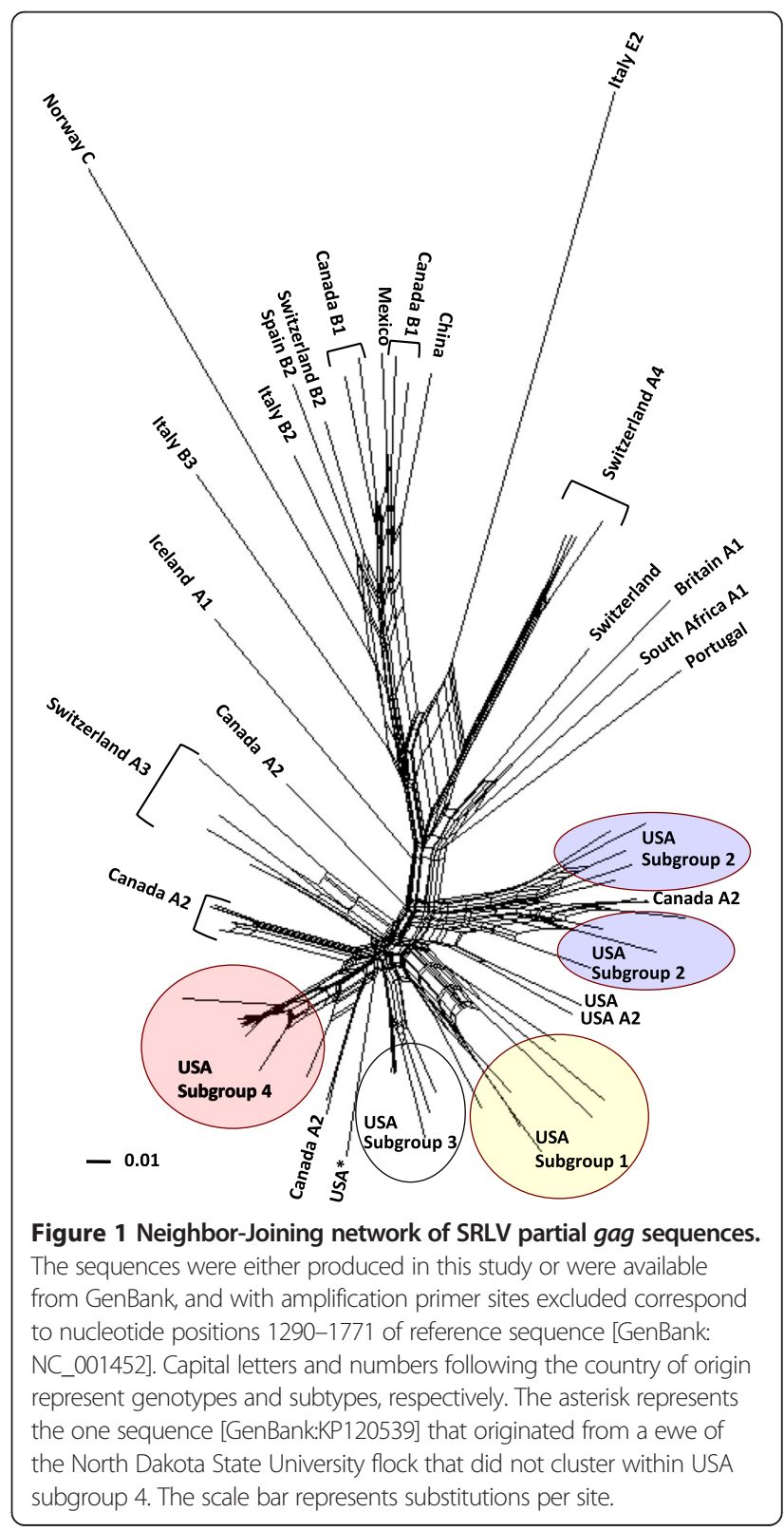




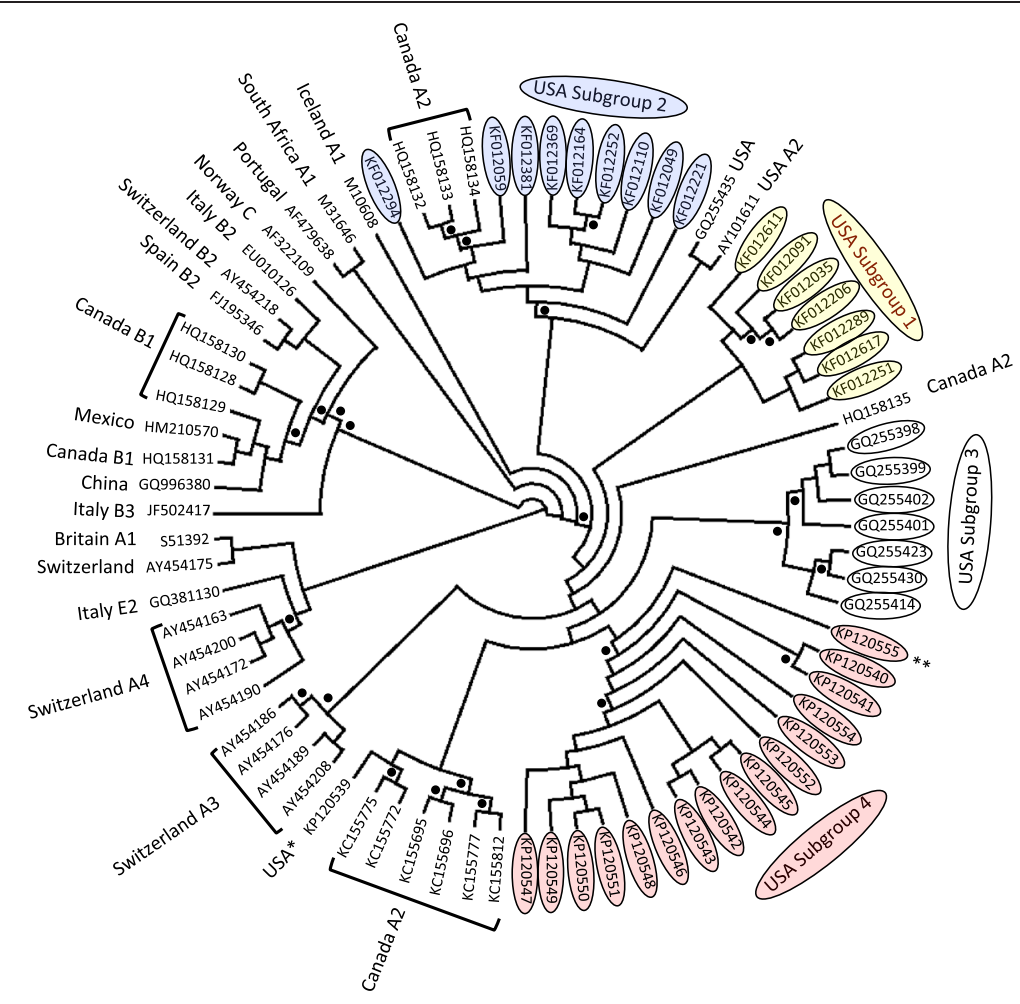

Figure 2 Bootstrapped Neighbor-Joining tree of SRLV partial gag sequences. The tree was produced from the same alignment used to produce the network in Figure 1. Like Figure 1, capital letters and numbers following the country of origin represent genotypes and subtypes, respectively. Outer taxonomic numbers represent GenBank accession numbers. Black dots represent bootstrap values greater than $80 \%$. The single asterisk represents the one sequence that originated from an ewe of the North Dakota State University flock that did not cluster within USA subgroup 4. The double asterisk represents one sequence that clusters with subgroup 4 sequences but is not supported within the clade with a bootstrap equal to or greater than $80 \%$. USA subgroups 1 and 2 both contain recombinant sequences that impact bootstrap support [13]. The tree is drawn as a circular cladogram and does not have a scale bar.

Neighbor-Joining tree was constructed to evaluate clade support with bootstraps, although Neighbor-Joining trees do not account for recombinant sequences. The network was constructed in SplitsTree (version 4.12.3) [26]. The tree was constructed in PHYLIP [27] using the programs Seqboot, Dnadist, Neighbor, and Consense, and viewed in Dendroscope [28]. Both the network and the tree were produced from a gag alignment generated with ClustalW in MacVector (version 12.0.6), with an F84 model of substitution and a transition/transversion ratio of two. The tree was bootstrapped with 1000 pseudoalignments. Sequence representatives of SRLV subgroups 1 and 2 were included in the analyses, as were those of what we describe as subgroup 3, which infected a flock of sheep in the Western United States [29], and has not been tested for an association with TMEM154 genotypes.

Of the North Dakota proviral gag sequences, 16 of 17 sequences clustered together in both the Neighbor-Net phylogenetic network and the Neighbor-Joining tree, indicating that a distinct SRLV subgroup infected members of the flock (USA Subgroup 4, Figures 1 and 2). Additionally, within the Neighbor-Joining tree, 15 of 16 sequences within the clade were supported by a bootstrap value greater than $80 \%$, delineating a clear genetic distinction of these strains from all others in the tree as a subgroup (USA Subgroup 4, Figure 2). The gag sequences from both of the infected TMEM154 "4,4" diplotype ewes placed in this subgroup, as did the sequences from ewes with TMEM154 "1,1", "1,2", "1,4", and "2,4" diplotypes (Figure 2, Table 2). This demonstrates that SRLVs of subgroup 4 are not restricted to infecting only sheep with TMEM154 "4,4" diplotypes. Both the network and the tree show that USA subgroups 1 , 2, 3, and 4 either contain or are flanked by genotype A, subtype A2 sequences. Additionally, the NeighborJoining tree has two bootstrap values greater than $80 \%$ that collectively support the clustering of all four USA subgroups with A2 sequences, with subtype A3 sequences from Switzerland comprising a related but separate clade (Figure 2). This indicates that all four USA subgroups are members of the A2 subtype.

The one SRLV gag sequence from a member of the North Dakota flock that was distinct from subgroup 4 originated from an ewe with a TMEM154 1,2 diplotype 
that was born in 2007, most likely in South Dakota. This ewe was introduced into the North Dakota flock in 2009. It is possible that she was infected with an SRLV prior to her introduction to the North Dakota flock.

\section{Discussion}

Subgroup 4 SRLVs can infect sheep with TMEM154 "4,4" diplotypes that are homozygous for the TMEM154 A4A53 mutation, as well as sheep that do not have haplotype 4. This indicates that subgroup 4 SRLVs do not require functional TMEM154 to infect sheep, and may be able to infect sheep with any TMEM154 diplotype. The mechanism(s) or host receptors that subgroup 4. SRLVs use to infect sheep in the absence of functional TMEM154 are unknown. Additionally, whether or not other SRLV subgroups infect cells in the same manner as subgroup 4 members at low frequency is also unknown. Additional barriers to infection that are independent of the TMEM154 locus may be required to prevent infection of sheep by subgroup 4 SRLVs.

All four SRLV subgroups that have been identified in the U.S. place within the A2 subtype. SRLV genotype A is highly diverse with 15 subtypes currently known [23]. To better understand the context of ovine TMEM154 allele associations with SRLV infection susceptibility, it would be interesting to know if SRLV members of other A subtypes, genotypes B-E, and any circulating recombinant forms vary by an association with TMEM154 alleles, including an ability to infect sheep with TMEM154 "4,4" diplotypes. Additionally, it would be beneficial to obtain full-length genomic sequences from members of the SRLV subgroups to identify viral alleles that are biologically responsible for TMEM154 associations, potential interactions, or lack thereof. Ultimately, knowledge at this level could lead to precision control of ovine SRLV infection through genetic management of both the host and the pathogen.

\section{Additional file}

Additional file 1: gag sequences used for phylogenetic trees of Figures 1 and 2. Table containing the following information for the gag sequences used to construct the phylogenetic trees of Figures 1 and 2; GenBank accession number, genetic subgroup affiliation, phylotype, production in this study, country of origin.

\section{Competing interests}

The authors declare that they have no competing interests.

\section{Authors' contributions}

Conceived and designed the experiments; MLC, RR, GS, MPH, AW, GPH, CGCM, TPLS, KAL. Performed the experiments; GS. Contributed reagents/ materials/analysis tools; MLC, RR, GS, MPH, KAL. Analyzed the results; MLC, RR, GS, MPH, AW, GPH, CGCM, TPLS, Wrote the manuscript; MLC. Revised the manuscript with critical intellectual content; MLC, RR, GPS, MPH, AW, GPH, CGCM, TPLS, KAL. All authors read and approved the final manuscript.

\section{Acknowledgments}

This work was supported by the Agricultural Research Service and by funding from the North Central Region-Sustainable Agricultural Research and Education program. We thank Jan Watts for secretarial support. The use of product and company names is necessary to accurately report the methods and results; however, the United States Department of Agriculture (USDA) neither guarantees nor warrants the standard of the products, and the use of names by the USDA implies no approval of the product to the exclusion of others that may also be suitable. The USDA is an equal opportunity provider and employer.

\section{Author details}

${ }^{1}$ United States Department of Agriculture (USDA) Agricultural Research Service (ARS), U.S. Meat Animal Research Center (USMARC), State Spur 18D, Clay Center, NE 68933, USA. ²Department of Animal Sciences, North Dakota State University, Fargo, ND 58108-6050, USA.

Received: 25 November 2014 Accepted: 4 February 2015

Published online: 05 March 2015

\section{References}

1. Leroux C, Cruz J, Mornex J-F (2010) SRLVs: A genetic continuum of lentiviral species in sheep and goats with cumulative evidence of cross species transmission. Curr HIV Res 8:94-100

2. Patton KM, Bildfell RJ, Anderson ML, Cebra CK, Valentine BA (2012) Fatal Caprine arthritis encephalitis virus-like infection in 4 rocky mountain goats (Oreamnos americanus). J Vet Diagn Invest 24:392-396

3. Erhouma E, Guiguen F, Chebloune Y, Gauthier D, Lakhal LM, Greenland T, Mornex JF, Leroux C, Alogninouwa T (2008) Small ruminant lentivirus proviral sequences from wild ibexes in contact with domestic goats. J Gen Virol 89:1478-1484

4. Ryan S, Tiley L, McConnell I, Blacklaws B (2000) Infection of dendritic cells by the Maedi-Visna lentivirus. J Virol 74:10096-10103

5. Pépin M, Vitu C, Russo P, Mornex J-F, Peterhans E (1998) Maedi-visna virus infection in sheep: a review. Vet Res 29:341-367

6. Blacklaws BA, Harkiss GD (2010) Small ruminant lentiviruses and human immunodeficiency virus: cousins that take a long view. Curr HIV Res 8:26-52

7. Pritchard GC, Dawson M (2000) Maedi-visna. In: Martin WB, Aitken ID (ed) Diseases of Sheep, 3rd edition. Oxford: Blackwell Science, Osney Mead, Oxford, UK, pp 187-191

8. Gudnadóttir M, Demosthenous A, Hadjisavvas T (2013) Vaccination delays maedi-visna lentivirus infection in a naturally-infected sheep flock. BMC Vet Res 9:16

9. Keen JE, Hungerford LL, Littledike ET, Wittum TE, Kwang J (1997) Effect of ewe ovine lentivirus infection on ewe and lamb productivity. Prev Vet Med 30:155-169

10. Reina R, Berriatua E, Luján L, Juste RA, Sánchez A, de Andrés D, Amorena B (2009) Prevention strategies against small ruminant lentiviruses: an update. Vet J 182:31-37

11. Clements JE, Zink MC (1996) Molecular biology and pathogenesis of animal lentivirus infections. Clin Microbiol Rev 9:110-117

12. Heaton MP, Clawson ML, Chitko-McKown CG, Leymaster KA, Smith TP, Harhay GP, White SN, Herrmann-Hoesing LM, Mousel MR, Lewis GS, Kalbfleisch TS, Keen JE, Laegreid WW (2012) Reduced lentivirus susceptibility in sheep with TMEM154 mutations. PLOS Genet 8:e1002467

13. Sider LH, Heaton MP, Chitko-McKown CG, Harhay GP, Smith TPL, Leymaster KA, Laegreid WW, Clawson ML (2013) Small ruminant lentivirus genetic subgroups associate with sheep TMEM154 genotypes. Vet Res 44:64

14. White SN, Mousel MR, Herrmann-Hoesing LM, Reynolds JO, Leymaster KA, Neibergs HL, Lewis GS, Knowles DP (2012) Genome-wide association identifies multiple genomic regions associated with susceptibility to and control of ovine lentivirus. PLOS One 7:e47829

15. Leymaster KA, Chitko-McKown CG, Clawson ML, Harhay GP, Heaton MP (2013) Effects of TMEM154 haplotypes 1 and 3 on susceptibility to ovine progessive pneumonia virus following natural exposure in sheep. J Anim Sci 91:5114-5121

16. Heaton MP, Kalbfleisch TS, Petrik DT, Simpson B, Kijas JW, Clawson ML, Chitko-McKown CG, Harhay GP, Leymaster KA, Consortium ISG (2013) Genetic testing for TMEM154 mutations associated with lentivirus susceptibility in sheep. PLoS One 8:e55490 
17. Herrmann LM, Cheevers WP, McGuire TC, Adams DS, Hutton MM, Gavin WG, Knowles DP (2003) Competitive-inhibition enzyme-linked immunosorbent assay for detection of serum antibodies to caprine arthritis-encephalitis virus: diagnostic tool for successful eradication. Clin Diagn Lab Immunol 10:267-271

18. Ewing B, Hillier L, Wendl MC, Green P (1998) Base-calling of automated sequencer traces using phred I Accuracy assessment. Genome Res 8:175-185

19. Ewing B, Green P (1998) Base-calling of automated sequencer traces using phred II Error probabilities. Genome Res 8:186-194

20. Gordon D, Abajian C, Green P (1998) Consed: a graphical tool for sequence finishing. Genome Res 8:195-202

21. Shah C, Boni J, Huder JB, H-R. V, Muhlherr J, Zanoni R, Miserez R, Lutz H, Schupbach J: Phylogenetic analysis and reclassification of caprine and ovine lentiviruses based on 104 new isolates: evidence for regular sheep-to-goat transmission and worldwide propagation through livestock trade. Virology 2004, 319:12-26

22. Grego E, Bertolotti L, Quasso A, Profiti M, Lacerenza D, Muz D, Rosati S (2007) Genetic characterization of small ruminant lentivirus in Italian mixed flocks: evidence for a novel genotype circulating in a local goat population. J Gen Virol 88:3423-3427

23. Kuhar U, Barlič-Maganja D, Grom J (2013) Phylogenetic analysis of small ruminant lentiviruses detected in Slovenia. Vet Microbiol 162:201-206

24. L'Homme Y, Leboeuf A, Arsenault J, Fras M (2015) Identification and characterisation of an emerging small ruminant lentivirus circulating recombinant form (CRF). Virology 475:159-171

25. Santry LA, de Jong J, Gold AC, Walsh SR, Menzies PI, Wootton SK (2013) Genetic characterization of small ruminant lentiviruses circulating in naturally infected sheep and goats in Ontario, Canada. Virus Res 175:30-44

26. Huson DH, Bryant D (2006) Application of phylogenetic networks in evolutionary studies. Mol Biol Evol 23:254-267

27. PHYLIP (Phylogeny Inference Package) version 3.69: [http://evolution. genetics.washington.edu/phylip.html]

28. Huson DH, Richter DC, Rausch C, Dezulian T, Franz M, Rupp R (2007) Dendroscope: an interactive viewer for large phylogenetic trees. BMC Bioinformatics 8:460

29. Herrmann-Hoesing LM, Broughton-Neiswanger LE, Gouine KC, White $S N$, Mousel MR, Lewis GS, Marshall KL, Knowles DP (2010) Evaluation of a caprine arthritis-encephalitis virus/maedi-visna virus indirect enzyme-linked immunosorbent assay in the serological diagnosis of ovine progressive pneumonia virus in U.S. sheep. Clin Vaccine Immunol 17:307-310

\section{Submit your next manuscript to BioMed Central and take full advantage of:}

- Convenient online submission

- Thorough peer review

- No space constraints or color figure charges

- Immediate publication on acceptance

- Inclusion in PubMed, CAS, Scopus and Google Scholar

- Research which is freely available for redistribution 